Part of Journal of Research of the National Bureau of Standards, Volume 35, August 1945

\title{
THIN-WALLED ALUMINUM BETA-RAY TUBE COUNTERS
}

\author{
By Burrell W. Brown and L. F. Curtiss
}

\begin{abstract}
A description is given of aluminum-tube Geiger-Müller counters having a wall thickness of 0.004 inch and constructed from commercially available tooth-paste tubes. These tubes as furnished are in the hard temper and have uniform wall thickness, which enable them to stand complete evacuation without a tendency to collapse. By copperplating the aluminum it is possible to soft-solder fittings to the tube to construct a counter that can be permanently sealed after filling and that will maintain its characteristics over a long period. The procedure reduces the cost of making this type of counter, as the aluminum tubes are inexpensive, and very simple operations are required in the construction of the counters.
\end{abstract}

\section{CONTENTS}

I. Introduction

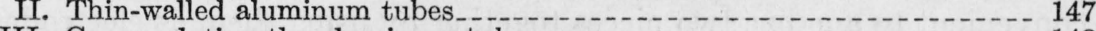

III. Copperplating the aluminum tube

IV. Construction of the Geiger-Müller counter

\section{INTRODUCTION}

An economical method of making thin-walled aluminum GeigerMüller counter tubes for the measurement of beta rays would greatly increase the usefulness of this type of instrument in the field of radioactivity. Present methods require, the boring of metal tubes or rods ${ }^{1}$ to a thin wall. This is a delicate and expensive operation, and the thinnest walls obtainable are approximately 0.007 inch. Thin-walled counters have also been made by drawing glass tubing to a thin-walled section and silvering the inside. ${ }^{2}$ This procedure does not give a very uniform wall, which is usually of a thickness greater than that corresponding to 0.007 -inch aluminum. Other methods require the use of wax seals, which do not yield tubes of very long life as the organic vapors commonly used in filling counters attack most waxes.

\section{THIN-WALLED ALUMINUM TUBES}

It has recently been noted that thin-walled aluminum tubes quite suitable for the construction of counters are commercially available. A typical tube is $5 / 8$ inch in diameter and $4 \frac{1}{2}$ inches long, with walls $0.0044 \pm 0.0004$ inch in thickness. The walls are uniform throughout

\footnotetext{
1 J. R. Dunning and S. M. Skinner, Rev. Sci. Instr. 6, 243 (1935); J. Halpern and O. C. Simpson, 8, 172 (1937)

${ }_{2}^{2}$ A. H. Barnes, Rev. Sci. Instr. 7, 107 (1936); J. C. Wang, J. F. Marvin, and K. W. Stenstrom 13, 81 (1942).
} 
the length and circumference within the limits indicated. These tubes are made in quantity as containers for such materials as tooth-paste and are furnished with one end fitted with the conventional screw cap and the opposite end open to the full diameter of the tube. Made by mass-production methods these tubes are inexpensive and of very uniform dimensions, and therefore are suitable as a component of a beta-ray counter. They are in the hard temper, which enables them to withstand complete evacuation with no tendency to collapse.

\section{COPPERPLATING THE ALUMINUM TUBE}

It is of advantage to construct counters that can be filled and sealed permanently so that they will maintain their characteristics over considerable periods of time. This requires the elimination of wax seals, gaskets, and similar arrangements. To accomplish this with the aluminum-tube counters, it has been found desirable to plate the aluminum with copper to permit the use of soft solder in joining the parts. There are several methods by which an adherent plating of copper can be applied to aluminum. For the benefit of those who may desire to construct such counters, the method of plating found most convenient is described.

The first step is to clean the aluminum surfaces to be plated in a strong solution of potassium hydroxide, immersing the aluminum until a smooth film of water will spread over it uniformly, indicating that the aluminum surface is clean. The next step is to anodize the aluminum surface. After rinsing all the potassium hydroxide solution from the aluminum, it is used as an electrode in a solution of 10- to 15percent oxalic acid to produce an anodic film on the surface. It is convenient to anodize two pieces together by using them as electrodes connected to the alternating-current supply through a variable-voltage transformer. Initially, the voltage applied should be of the order of 1 or 2 volts, and this may be increased to around 50 volts as the anodic film develops. Care should be taken to hold the voltage low enough at all times to avoid heating of the solution by the current. After 15 to 20 minutes the aluminum is removed, rinsed in cold water, and etched for a few seconds in a 1-percent hydrofluoric acid solution until a slight evolution of gas is apparent. It is then immediately rinsed in cold water, and the surface is ready for plating. The usual copper sulfate solution, to which a small amount of sulfuric acid has been added, is used for plating. The plating of a layer of copper a few thousandths of an inch in thickness requires about 20 minutes. In constructing the counters, both ends of the tubes are plated with copper. If copper is deposited over a larger area than is desired, the excess may be removed at any time by etching with strong nitric acid, which has little effect on the aluminum.

The etching of the anodic coating with hydrofluoric acid may be eliminated if care is taken to develop a thin coating in the anodizing process. The proper thickness is obtained by interrupting the anodizing process when the potential reaches about 2 volts. Some difficulty may be encountered in determining the proper conditions to secure an adherent coating of copper by use of this alternative method. 


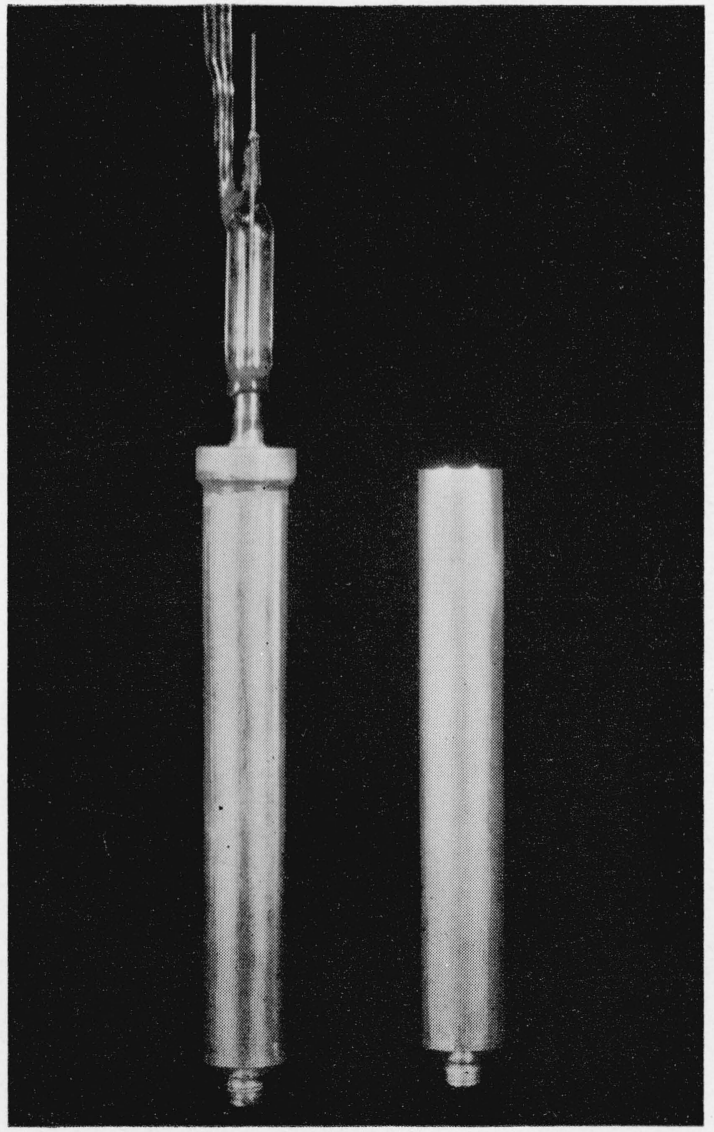

Figure 3.-Completed counter. 


\section{CONSTRUCTION OF THE GEIGER-MÜLLER COUNTER}

The assembly of the counter is shown in cross section in figure 1. The circular end of the tooth-paste tube, $T$, is closed by the copper bushing, $B$, which is soft soldered to the plated aluminum tube, as indicated. The bushing is fitted with a $1 / 4$-inch Kovar tube, $K$, silversoldered in an axial hole, as shown. A short glass tube sealed to $K$ provides a support for one end of the central wire, $W$, and also carries a side tube for evacuating, filling, and sealing the counter. The glass tube is continued inside of $K$ to form a sleeve around the central wire. The opposite end of the aluminum tube is closed by a copper plug, $P$, soldered into the small tubular opening of the tube. The plug is drilled to take a small piece of Kovar wire, which carries a glass bead, $G$, to serve as a support for the central wire at this end. The plug and wire are soft soldered in one operation to the aluminum tube, previously copperplated at this point.

The order of assembly found convenient is first to silver solder tube $K$, into copper bushing, $B$. The glass tubing is then sealed into $K$ and the bushing, $B$, soft soldered into tube, $T$. The central wire system is then made up and lowered into $T$ to protrude through the screw-cap end. Copper plug, $P$, is soft soldered to the short Kovar wire and then into $T$. The Kovar wire, $R$, is then pulled into position at the opposite

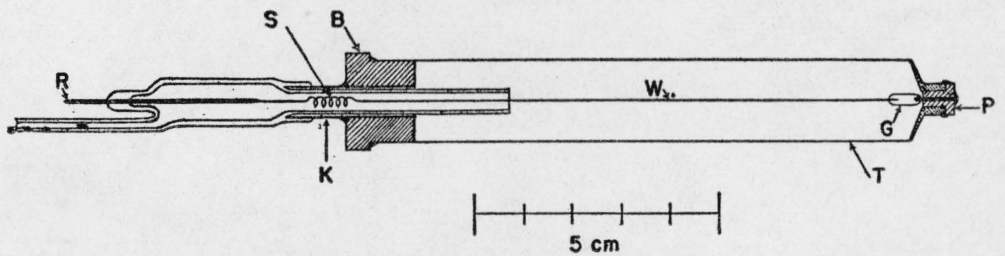

Figure 1.-Cross section of assembly of counter.

end and sealed into the glass. The dimensions are such that there is a moderate tension on the spring, $S$. If the dimensions are carefully chosen this spring may be eliminated.

The performance of the finished counter depends, of course, on the type of filling used. In the counter described here, the usual alcoholargon mixture has been found to yield plateaus and thresholds similar to other types of Geiger-Müller counters containing this mixture. A slope of 0.1 percent per volt is readily obtained. A curve showing the variation of counting rate with voltage applied to the counter is shown in figure 2. This curve is maintained for several months, which is as long as the counters were under observation. Experience indicates that a counter will leak occasionally as a result of imperfect soldering. This can be quickly repaired. In a few cases it was also found that the aluminum tooth-paste tubes have a small leak, probably due to pin holes. Perhaps 5 percent of the tubes may have this defect, which can be detected by preliminarv evacuation. 


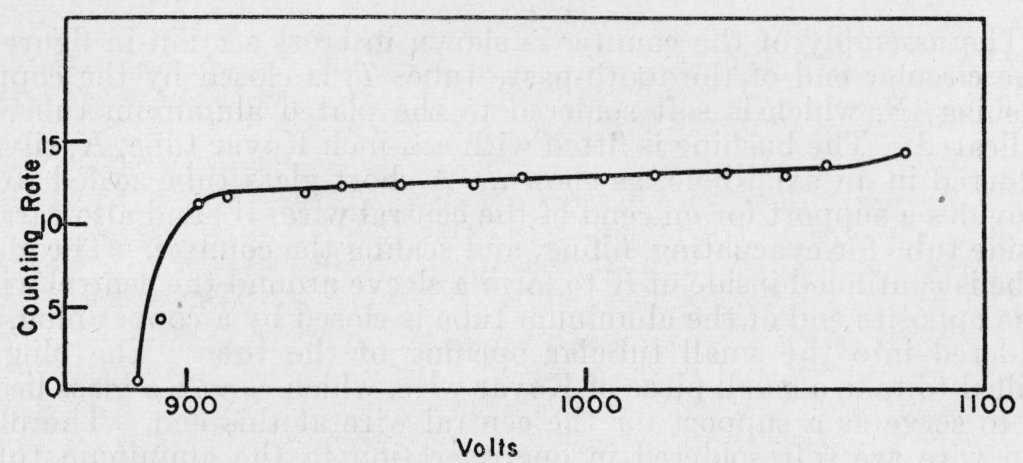

FIGURE 2.-Variation of counting rate with voltage applied to counter.

A completed counter, ready for filling, and an empty tube are shown in figure 3 . Aluminum tubes of other diameters but of approximately the same wall thickness and that do not collapse on evacuation are also available commercially.

Washington, May_4, 1945. 